http://dx.doi.org/10.4314/gjl.v6i2.1

\title{
DAGARA TONGUE-ROOT VOWEL HARMONY
}

\author{
Nerius Kuubezelle, George Akanlig-Pare
}

\begin{abstract}
Though tongue-root vowel harmony in many Ghanaian languages has been described, there still remain many others which have received little or no description at all. Dagara, a dialect of Dagaare a Mabia language, is one of such dialects. This paper presents a description of Dagara tongue-root vowel harmony using Autosegmental Theory. The paper reveals that Dagara has bi-directional [ATR] harmony with [+ATR] vowels being the triggers of the harmonic process. In the progressive harmony processes, the [+ATR] feature of stem vowels causes [-ATR] vowels of suffixes to change to harmonize with them; in a regressive harmony process, [+ATR] vowels of the suffixes have dominance over those of stems and cause them to change to harmonize. The paper also shows that [f] is an opaque consonant, and blocks [+ATR] harmony spread from stems to suffix vowels. The opacity effect is however unidirectional as there is no evidence of such restriction in left-to-right harmony. The paper concludes that, there is a strict co-occurrence restriction on vowels of words in Dagara.
\end{abstract}

Keywords: Mabia language, Tongue-root vowel, Autosegmental Theory, Progressive harmony, Regressive harmony 


\subsection{Introduction}

This paper discusses tongue-root vowel harmony phenomenon in Dagara, with the view of contributing to a holistic development of the Dagaare language in Ghana. Dagaare belongs to the northern branch of the Western Oti-Volta group of the Gur branch of the Niger-Congo language family (Bendor-Samuel 1971). Dagaare has four major dialects which exhibit obvious linguistic variations at phonological, lexical and grammatical levels (Dakubu 2005). The Dagaare language shares very close affinity with languages like Dagbanli, Moore, Gurene, Mampruli, Kusaal and Buli. Bodomo (1997) refers to these West Oti-Volta languages as Mabia, not only because they all belong to the Gur branch of the Niger-Congo language family, but more obviously because they all share some common lexical items such as ma 'mother' and bie bia 'child'.

The phenomenon of vowel harmony has been explained by various linguists. Goldsmith (1990) postulates that a vowel harmony system is one in which the vowels of a language are divided into two subsets with the condition that all vowels in a given word (or domain), generally must come from a single subset. Kenstowicz (1994) also explains that vowel harmony is a phonological state in which the vowels in a given domain share or harmonize for a particular feature. Clements (1976) further states that vowel harmony consists of a co-occurrence restriction upon the vowels that may occur in a word. In other words, all the vowels in a word must be drawn from one or another of two mutually exclusive sets.

Several studies have been carried out regarding this phenomenon in Ghanaian languages. Among them are Akanlig-Pare (1994) in Buli and Hudu (2013) in Dangbanli. Saanchi (1997) also discusses vowel harmony in Dagaare pointing out three types including ATR harmony, Rounding harmony, and Cross Height Vowel Harmony drawing data from the Central dialect of Dagaare. Dundaa (2013) discusses aspects of Birifor phonology including Tongue-Root vowel harmony, Cross-Height vowel harmony among others. Bemile (1985) touches briefly on Dagara tongue root vowel harmony, but this work is in German, which is not accessible and comprehensible to the many readers. This paper contributes to the existing literature by discussing Dagara tongue root vowel harmony system. It will show that the Dagara harmony system is unique, and manifests many features that are not in the other Dagaare dialects.

There are eighteen (18) vowel phonemes in Dagara, sub-categorized into eight (8) Advanced Tongue Root [+ATR] vowels which are: /i, e, u, o, i, ẽ, ũ, õ/, and eight (8) Retracted/Unadvanced Tongue Root [-ATR] vowels as follows: /ı, $\varepsilon, ~ \mho, ~ \jmath, ~ \tilde{\imath}, \tilde{\varepsilon}, \tilde{\mho}, \tilde{\jmath} /$. Two 
other vowels, /a, ã/, are considered as neutral by virtue of the fact that they co-occur with both [+ATR] and [-ATR] vowel(s) in some words, but they associate more frequently with the $[-\mathrm{ATR}]$ set of vowels. In poly-syllabic words in Dagara, there is strict co-occurrence restriction of the two sets of vowels, as described in Clements (1976). The vowels in words are selected from either of the two harmony systems. In the formation of words, when forms with vowels from the two different sets are juxtaposed, a harmony process is triggered to ensure that the vowels harmonize for a particular feature in line with Kenstowicz (1994) explanation. The harmonic processes in Dagara are bidirectional; the harmony spread is either progressive and spreads from stems to suffixes, or it is regressive and spreads mainly from dominant suffixes to stems or from one dominant stem to another stem in the case of compounds. The examples in (1) below illustrate the strict cooccurrence restriction of the two sets of vowels in some words in Dagara.

(1) Tongue root vowel harmony

$\begin{array}{llll}{[+\mathrm{ATR}]} & \text { Gloss } & {[\text {-ATR] }} & \text { Gloss } \\ \text { túór } & \text { 'load' } & \text { tơór } & \text { 'mortar' } \\ \text { kúór } & \text { 'funeral' } & \text { kùòr } & \text { 'gourd' } \\ \text { púó } & \text { 'farm' } & \text { pùò } & \text { 'within' } \\ \text { gbébír } & \text { 'toe' } & \text { tíz̀ykublu } & \text { 'beard' } \\ \text { gbồgbókyìlé } & \text { 'jackal' } & \text { nàfóbéglìkèr } & \text { 'sandals' (slippers) }\end{array}$

The data for this study is a blend of primary data, secondary data from published works and native-speaker knowledge. The primary data was elicited from native speakers of the Dagara dialect in villages including Kyebogo, Nandom and Hamile in the Upper West Region of Ghana, using the Summer Institute of Linguistics West African Area Wordlist 1 (Boone Douglas 1989). The analyses of the data are done qualitatively and represented using the Autosegmental Theory (AT) framework propounded by Goldsmith (1976). Autosegmental theory is an offshoot Generative Phonology theory which evolved initially to handle the problematic issues relating to tonal representations in linguistic analyses. Autosegmental phonology places phonological features on separate tiers and link them using Association Lines at a Skeletal Tier. From tonal representation, Autosegmental theory was extended to cover all phonological processes such as vowel harmony (Sagey 
1986). The Autosegmental representation makes it possible to demonstrate the naturalness of assimilatory processes since it shows how features spread from one tier to affect features on other tiers. Deletion is also naturally shown by delinking association lines that link features on different tiers.

The rest of the sections in this paper shall focus on discussions of data in the following order: section 2 discusses data on progressive harmonic processes; section 3 discusses data on regressive harmonic process; section 4 focuses on consonant opacity in the harmonic processes; and section 5 constitutes the conclusion.

\subsection{Progressive Harmonic Processes}

This section discusses harmony between verb stem and progressive suffix, verb stem and nominal suffix, noun stem and nominal suffix, and verb stem and the second part of the discontinuous negative morpheme.

\subsection{Harmony Between Verb Stem and Progressive Suffix}

In Dagara, the progressive suffix in its underlying form is the mid-vowel [- $\varepsilon$ ] of [-ATR] set, where the verb stem is of a CVC syllable shape, with the coda consonant being a liquid. But when the verb stem is an open syllable (CV) type, the suffix is preceded by an alveolar trill $/ \mathrm{r} /$ and surfaces as [-re], or it is preceded by an alveolar nasal $/ \mathrm{n} /$ as in [-ne], where the verb stem ends in a nasal vowel.

However, when the progressive or imperfect suffix is added to a [+ATR] verb stem, it is caused to change to harmonize with the [+ATR] quality of the verb stem to become $-\mathrm{e}$, - re, or -ne. The data in 2 shows the progressive harmonic process between [+ATR] verb stem and the progressive suffix.

(2) $[+\mathrm{ATR}]$ verb stem and progressive suffix

a.

Tongue Root Tier
Skeletal Tier
Segmental Tier

Underlying Form

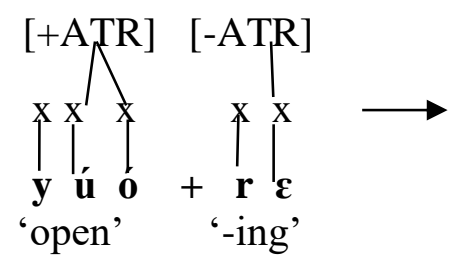

[+ATR] Spreading

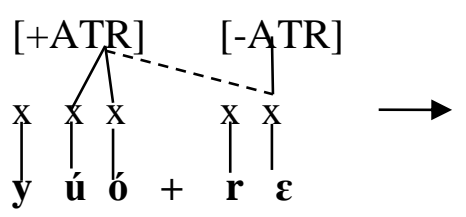


[-ATR] Delinking

Tongue Root Tier

Skeletal Tier

Segmental Tier

b.

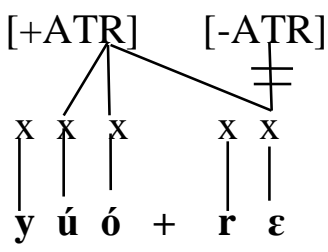

Underlying Form

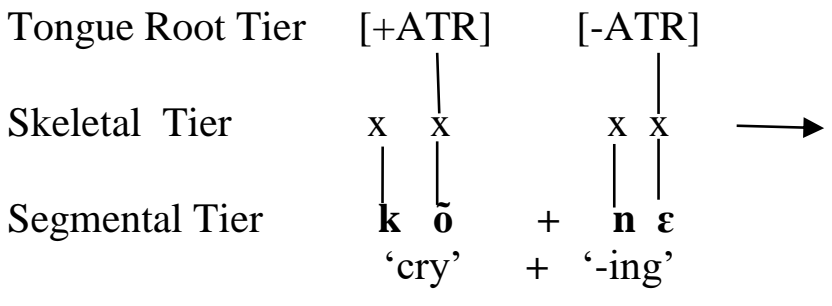

[-ATR] Delinking

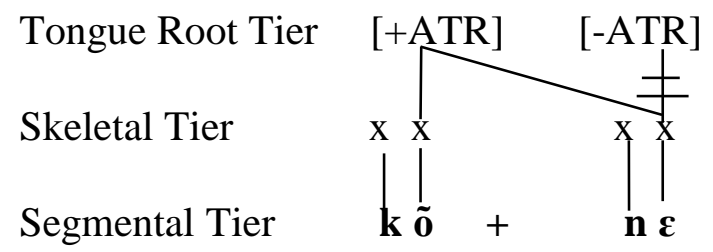

Output Form

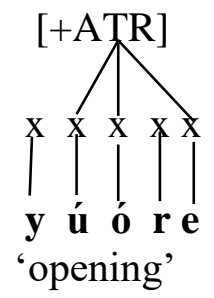

[+ATR] Spreading

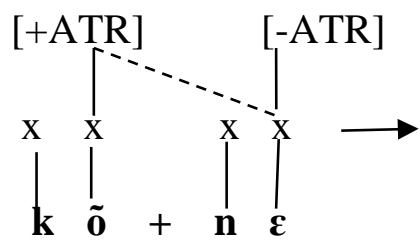

Output Form

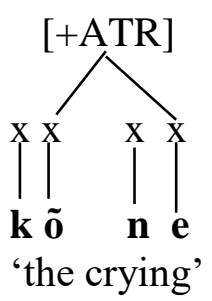

\subsection{Verb Stem and Nominal Suffix Harmony}

Some verbal nouns are derived in Dagara by simply adding nominal suffixes. One of the suffixes is $-\mho$, in the underlying form but when the verb stem vowel is a [+ATR], it surfaces as $-\mathrm{u}$, in harmony with the stem vowel quality. The harmony process however fails if the voiceless labiodental fricative /f/ intervenes between the suffix vowel and the stem vowel. This opacity phenomenon is discussed in 4.0. The data in (3) show examples of verbal noun derivation process, where the nominal suffix is caused to change from [ATR] to [+ATR] to harmonize with the verb stem vowels. 
(3) $[+$ ATR $]$ Verb stem harmonizing [-ATR] nominal suffix
Underlying Form
[+ATR] Spreading
Tongue Root Tier
Skeletal Tier
Segmental Tier

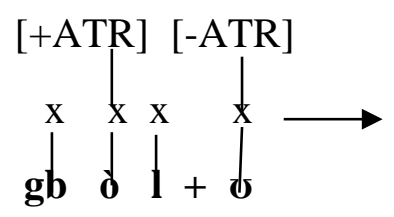
[+ATR $] \quad[-\mathrm{ATR}]$

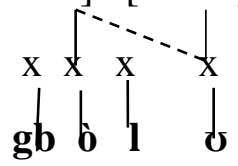
'penetrate' + N.suffix
[-ATR] Delinking
Output Form
Tongue Root Tier
Skeletal Tier
Segmental Tier
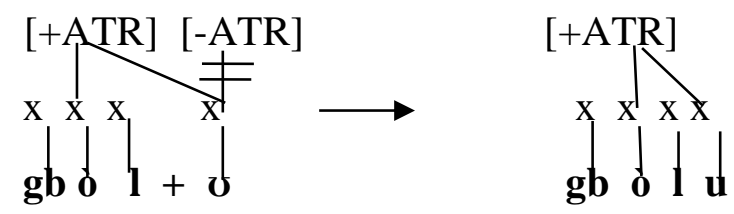
'the penetration'

\subsection{Noun Stem and Nominal Suffix Harmony}

Some abstract nouns in Dagara are also derived from concrete nouns by adding the suffix $-\mho$ or $-1 \mho$ to them in the underlying form. But when combined with a [+ATR] noun stem they surface as $-\mathrm{u}$ in stems that end with a consonant, or $-\mathrm{lu}$ in stems that end with a vowel as the derivation in (4) shows.

(4) $[+\mathrm{ATR}]$ noun stem and nominal suffix harmony

Tongue Root Tier
Skeletal Tier
Segmental Tier
[-ATR] [-ATR] Delinking

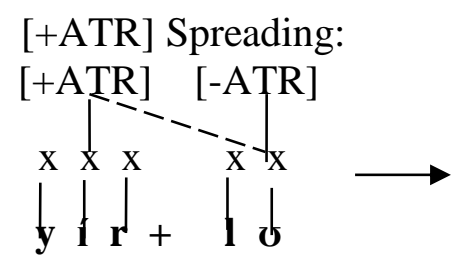

Segment Deletion 
Tongue Root Tier

Skeletal Tier

Segmental Tier

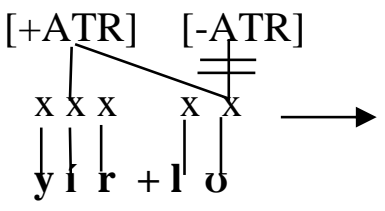

Vowel Lenghtening

Tongue Root Tier

Skeletal Tier

Segmental Tier

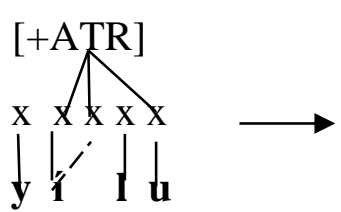

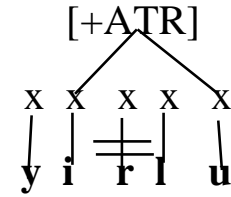

Output Form

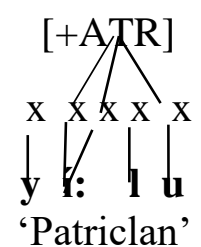

\subsection{Harmony Between Verb Stem and Second Negative Morpheme}

Negation in Dagara is expressed in the indicative and imperative by means of two discontinuous morphemes; ' $b \varepsilon . . . \varepsilon / \mathrm{l}$ ' and 'ta...e/l', respectively. The structural arrangements are similar to the structure of negation in French, where the verb is placed between the two negative morphemes. These morphemes are underlyingly [-ATR], but the second components of the morphemes change to [+ATR] when the verb has [+ATR] vowels, whilst the first component remains invariably [-ATR]. Thus, their allophonic versions are 'bc...e/I and 'ta ...e/i', for indicative and imperative, respectively.

The data in (5) below show that failure to trigger ATR harmony so that the [-ATR] quality of the second negative morpheme changes to harmonize with the [+ATR] value of the verb renders the clause ungrammatical. In (6), the harmony process is represented, showing the progressive spread of the [+ATR] feature of the verb to the second negative morpheme.

(5) Indicative

a. Uे be bòr $\varepsilon$ 3SG NEG loose NEG 'He / She did not get lost.'
Imperative

Ta bòr $\varepsilon$

NEG loose NEG

'Don't get lost.' 
b. Ù be bòr *e 'He / She did not get lost.'

c. ¿̀ be dó e 3SG NEG climb NEG 'He / She did climb.'

d. ¿̀ be dó * $\varepsilon$ 3SG NEG climb NEG

'He / She did not climb.'
Ta bə̀r *e

NEG loose NEG

'Don't get lost.'

Ta dó e

NEG climb NEG

'Don't climb.'

Ta dó $*_{\varepsilon}$

NEG climb NEG

'Don't climb.'

(6) Harmony across verb stem to second negative morpheme

$$
\text { Underlying Form [+ATR] Spreading }
$$

Tongue Root Tier: [-ATR] [+ATR] [-ATR]

Skeletal tier:

Segmental Tier:
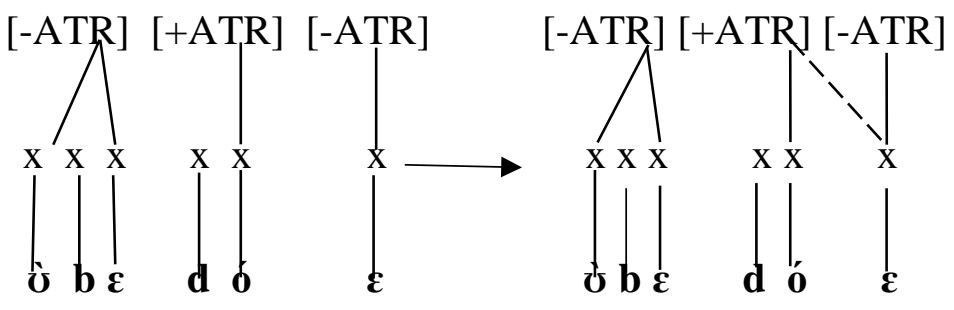

[-ATR] Delinking

Output Form

Tongue Root Tier: [-ATR] [+ATR] [-ATR]

Skeletal Tier:

Segmental Tier:

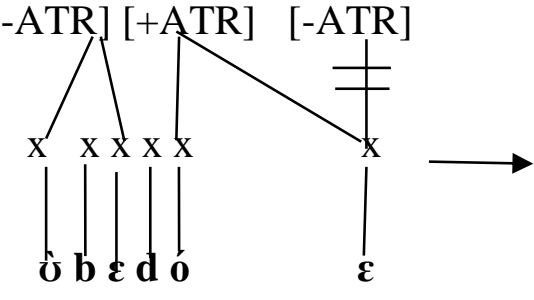

[-ATR] [+ATR]

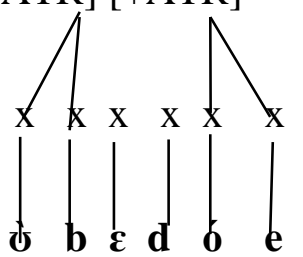

'He/She did not climb.' 


\subsection{Regressive Direction of Harmonic Process}

The Regressive harmonic process is triggered within two types of domains: one domain is a noun stem and a dominant diminutive suffix construction; the other is a noun + noun compound domain, where the second noun is dominant within the domain.

\section{1 [-ATR] Noun Stems and Diminutive Suffix Harmony}

In diminutive constructions in Dagara involving the diminutive suffix -le 'small' (li 'plural form'), the [+ATR] feature of the diminutive suffix spreads to the noun stem and causes stem vowels to harmonize with it if they are of the opposite value. Dundaa (2013) reports of a similar thing about Birifor, another dialect of Dagaare. In this domain, unlike the progressive harmony spread, the suffix vowel is dominant and therefore the spread is in a regressive direction to the stem. The representation in (7) below shows the regressive spread.

(7) $[$-ATR $]$ Noun stems and diminutive suffix harmony

Underlying Form

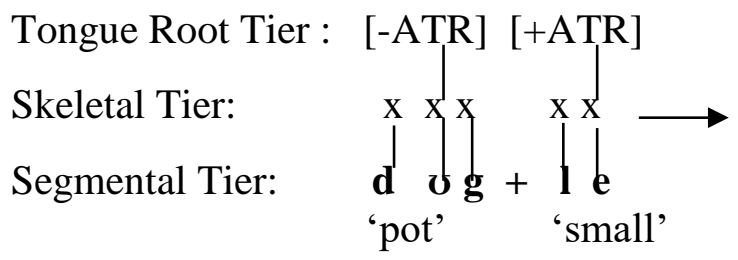

[-ATR] Delinking

Tongue Root Tier :

Skeletal Tier:

Segmental Tier:

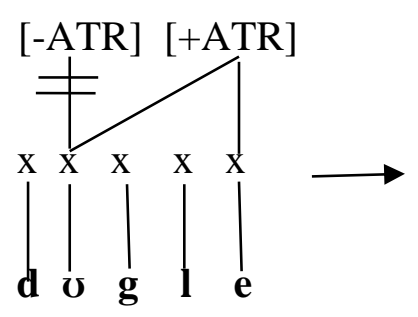

[+ATR] Left Ward Spread

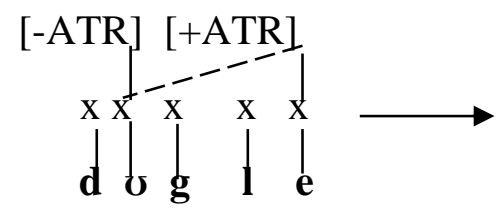

Output Form

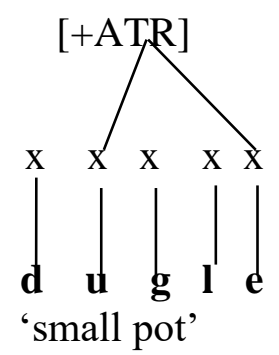




\subsection{Harmony within Compounds}

In Dagara compound words, it is common to have both stems of the compound having different tongue root vowels. This seems to be a real phenomenon, and it is manifested in a language like Buli (Akanlig-Pare 1994), Birifor (Dundaa 2013), and Waali (Abdul-Moomen 2015), where within the compound word, the ATR value of both stems may be the same or different. Akanlig-Pare (1994) for example explains that the failure to have a harmony process triggered so that the vowels of both stems of a compound are harmonized is due to the opacity effect created as a result of the adjacency of two-word boundaries, one at the right edge of the first stem, and the other on the left edge of the second stem. The examples in (8) show such compounds in Dagara.

(8) a. Same ATR value in compounds

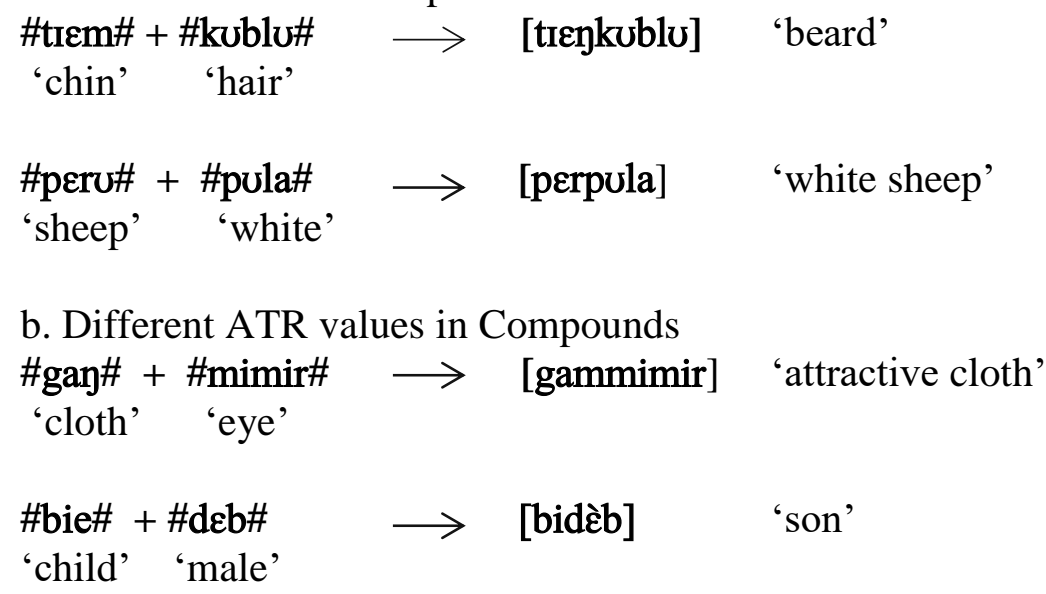

The examples in (8) show compounds where vowels of both stems have retained their ATR values. In (8a) both stems retain their [-ATR] values, while in (8b) there is a mixture of both [+/-ATR] vowels. In the case of $(8 \mathrm{~b})$ where we have a mixture of ATR values, the expectation is that one value will trigger the harmony process for both stems to surface with a uniform ATR value. This process however does not occur automatically.

However, in one instance of compounding involving a noun stem and the adjectival bir 'seed' (or its plural form bie 'seeds'), tongue root harmony is triggered. In this domain, the [+ATR] vowel of bir 'seed' is always dominant and thus causes the vowels of the 
preceding stem to harmonize in ATR value with it. The representation in (9) shows this marked harmony process in compounds in Dagara

(9) [-ATR] Noun stem and [+ATR] noun suffix harmony

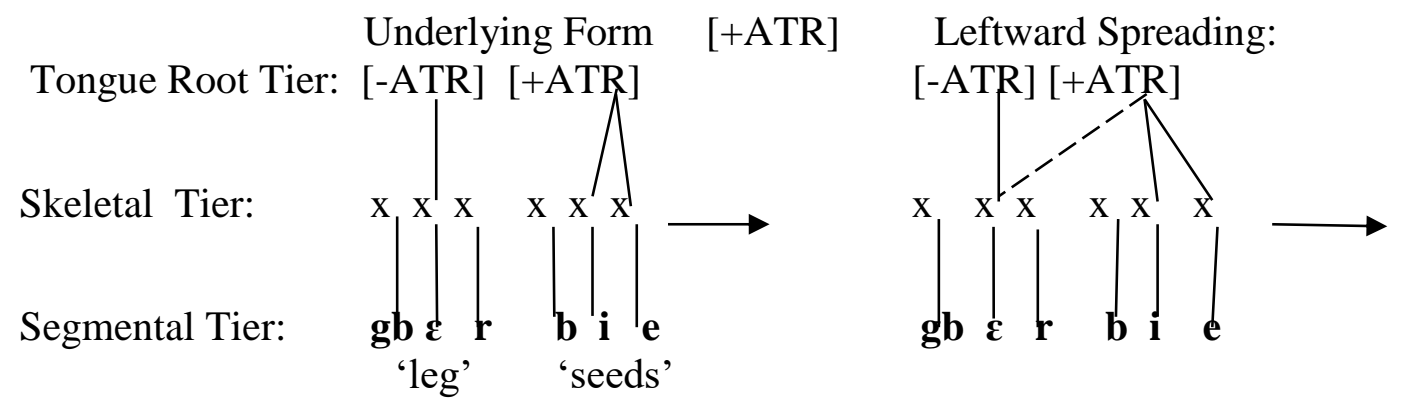

$$
\text { [-ATR] Delinking }
$$

\section{Segment Deletion}

Tongue Root Tier:
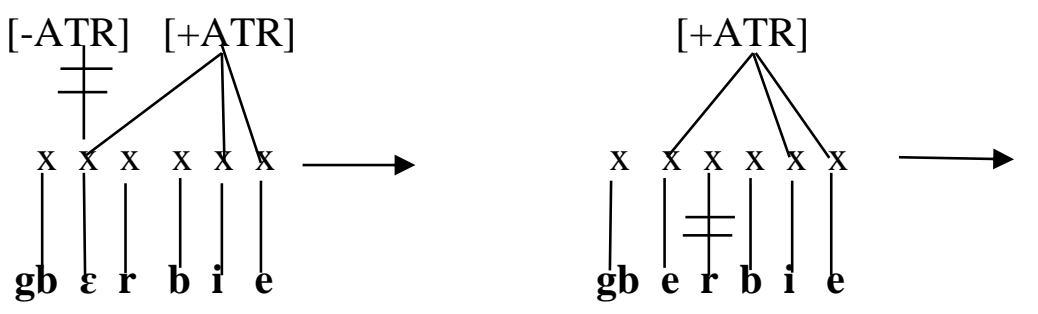

Segmental Tier

\section{Output Form}

Tongue Root Tier




\section{Consonant Opacity in The Harmonic Process}

As noted in 2.2, there is a constraint on the spreading of the [+ATR] vowel quality from verb stem onto a nominal suffix if the voiceless labiodental fricative / $/$ / is realized in a position between the trigger domain and the target vowel in the suffix. In this case, the variant of the nominal suffix $[-f \mho]$ will not be affected by the presence of a [+ATR] in the noun stem. This opacity effect implies that /f/ is an opaque consonant in Dagara that can block the spreading of the [+ATR] feature from the stem to the suffix. Segment opacity effects on harmonic processes have been described in at least one other Gur language. Hudu (2013) for example, discusses such consonantal opacity in Dagbanli tongue-root harmony noting that, the continuant coronals $[1, \mathrm{~s}, \mathrm{~s}]$ block the spread of [+ATR] from root vowels to targets such as epenthetic vowels, affixes and cliticized vowels. The representation in (10) below shows the breakdown of the harmonic process as a result of the presence of /f/ in the onset of the nominal suffix. In this position, the spread of the [+ATR] feature is blocked from spreading to the [-ATR] suffix vowel.

(10) Opacity effect of /f/ on the harmonic process

Underlying form:

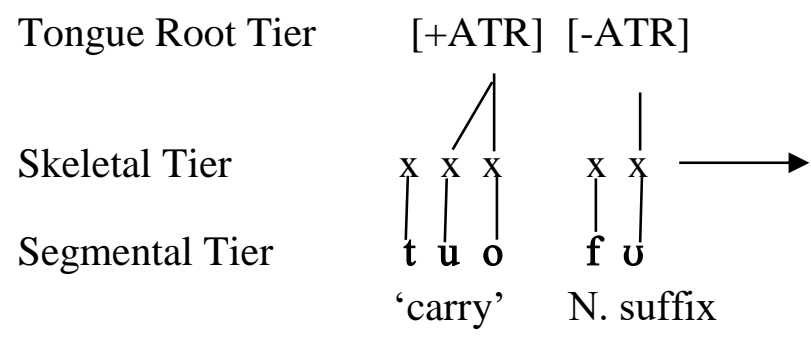

Output:
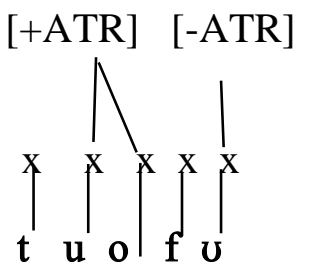

'the carrying'

\section{Conclusion}

Consistently, Dagara exhibits the strict type of vowel harmony involving the root of the tongue. This strict co-occurrence restriction is both the property of the vowel as well as a process. The harmonic processes occur bi-directionally; progressively from stems to suffixes and regressively from suffixes to stems and between stems in a unique word formation process. Progressive stem vowel triggered harmonic process targets [-ATR] vowels in suffixes. Regressive suffix or stem triggered harmonic processes target [-ATR] 
vowels in stem. There is only one opaque consonant /f/ that blocks spreading of [+ATR] vowel feature from verb stems to a nominal suffix. These harmony processes all show that the $[+\mathrm{ATR}]$ feature is the dominant one in Dagara. 


\section{References}

Akanlig-Pare, George. 1994. Aspects of Buli Phonology. MPhil. Thesis. University of Ghana.

Akanlig-Pare, George. 2005. Buli Tonology: A Non-Linear Approach. Ph.D. Thesis, University of Ghana.

Bemile, Sebastian K. 1983. Dàgàrà Phoneme Contrast. 1. Africana Saraveinsia Linguistica. Nr.1. Saarbrücken: Universität des Saarlandes.

Bemile, Sebastian K.1984. Dàgàrà Phoneme Contrast. 2. Africana Saraveinsia Linguistica. Nr.1. Saarbrücken: Universität des Saarlandes

Bemile, Sebastian K. 1985. Grundzüge der Phonologie des Dàgàrà.Africana Saraveinsia Linguistica. Nr. 9. Saarbrücken: Universität des Saarlandes.

Bodomo, Adams. 1997. The Structure of Dagaare. Stanford Monographs in African Languages. California: CSLI Publications.

Bodomo, Adams. 2000. Dagaare. Languages of the World/Materials 165. Muenchen: Lincom Europa.

Boone, Douglas. 1989. Towards an African Area Standard Word List. Paper presented at the SILInternational Language Assessement Conference (ILAC), Horsley Green, England.

Clements, George N. 1979. The Description of Terraced-Level Tone Languages. Language. 55 (3), 536-558. Linguistic Society of America. http://www.jstor.org/stable/413317. 18/04/2013 $\underline{12: 25}$

Dakubu, Mary Esther Kropp. 2005. Collected Language Notes on Dagaare Grammar.Collected Language Notes (26). Institute of African Studies, Legon.

Dundaa, Mark. 2013. Aspects of Birifor Phonology. MPhil. Thesis, University of Ghana.

Goldsmith, J. A. 1990. Autosegmental and Metrical Phonology. Oxford: Basil Blackwell Ltd.

Hudu, Fusheini. 2013. Dagbani tongue-root harmony: triggers, targets, and blockers. Journal of African Languages and Linguistics. 34 (1), 47-73.

https://www.degruyter.com/downloadpdf/j/jall.2013.34.issue-1/jall-2013-0002/jall-20130002.xml

Kenstowicz, Michael. 1994. Phonology in Generative Grammar. USA: Blackwell Publishers.

Kuubezelle, Nerius. 2013. An Autosegmental Analysis of Phonological Processes in Dagara. M.Phil. Thesis, University of Ghana.

Saanchi, James A. 1997. The Vowel System of Dagaare. Gur Papers/ Cahier Voltaïques (2), 129135

Sagey, Elizabeth Carol. 1986. The Representation of Features and Relations in Non-Linear Phonology. Ph.D. Thesis, MIT. 